\title{
Pengaruh Senam Lansia terhadap Kualitas Hidup Lansia di Panti Werdha
}

\author{
Rian Yuliyana ${ }^{1}$, Jhonni Wahyudi ${ }^{2}$ \\ ${ }^{1,2}$ Sekolah Tinggi Ilmu Kesehatan Hang Tuah Tanjungpinang Jl. Baru Km. 08 \\ Tanjungpinang
}

Email: rhee_adek@yahoo.com

\begin{abstract}
Abstrak
Peningkatan populasi lansia berisiko terjadinya beberapa masalah kesehatan, baik masalah fisik, mental, sosial, dan timbulnya berbagai penyakit degenerative. Proses menua tetap menimbulkan permasalahan baik secara fisik, biologis, mental sosial ekonomi. Peningkatan penyakit akan menurunkan kualitas hidup lansia dan disinilah pentingnya adanya Panti Werdha. Tujuan dari penelitian ini untuk mengetahui pengaruh senam lansia terhadap kualitas hidup lansia di Lembaga Kesejahteraan Lansia Anugerah. Penelitian ini merupakan penelitian kuantitatif menggunakan desain Quasi Eksperimen dengan Pretest and Posttest without Control Group, pengambilan sampel pada penelitian ini menggunakan simple random sampling pada 10 responden dari 27 populasi lansia yang ada di Lembaga Kesejahteraan Lansia Anugerah. Data dianalisis dengan menggunakan statistik dan independent sample t-test. Hasil penelitian ini menunjukkan pengaruh yang signifikan antara senam lansia terhadap kualitas hidup lansia di Lembaga Kesejahteraan Lansia Anugerah ( $\rho$-value 0,014, $\rho<\alpha$ 0,05). Direkomendasikan untuk lansia agar secara rutin melaksanaan senam lansia minimal sekali dalam seminggu agar meningkatkan kualitas hidup.
\end{abstract}

Kata Kunci: senam, lansia, kualitas hidup

\footnotetext{
Rujukan artikel penelitian:

Yuliyana, R., Wahyudi,J. (2018). Pengaruh Senam Lansia terhadap Kualitas Hidup Lansia di Panti Werdha. Jurnal Ilmiah Keperawatan Indonesia. Vol. 1 (2): 51-62.
} 


\begin{abstract}
The increasing of elderly population has risk to several health problems, such as physical problems, mental, social, and different onset of degenerative diseases. It will make poor quality of life of elderly and make nursing home to be an important thing for elderly. The main purpose of this study was to determine the effect of gymnastics for elderly to quality life of elderly in the nursing home Lembaga Kesejahteraan Lansia Anugerah. Quasi-Experimental with the pretest and posttest without control group was empleyod involving 27 participants by random sampling at Lembaga Kesejahteraan Lansia Anugerah. Data analysis was used an independent sample t-test. The study showed that were statistically significant effect of gymnastic elderly to quality of life of elderly Anugerah ( $\rho$ value $0,014, \rho<\alpha 0,05$ ). It suggests that the elderly need to do gymnastics once a week to improve the quality of life.
\end{abstract}

Keywords: gymnastics, elderly, quality of life 


\section{PENDAHULUAN}

Peningkatan kesejahteraan sosial yang bertujuan pada peningkatan kualitas hidup individu dan masyarakat, termasuk kelompok lanjut usia (lansia) merupakan salah satu sasaran dalam pembangunan di Indonesia. Menurut Notoatmodjo (2007) mengemukakan lansia adalah tahap akhir siklus kehidupan. Lansia adalah kelompok orang yang sedang mengalami suatu proses perubahan yang bertahap dalam jangka waktu beberapa dekade. Peningkatan populasi lansia setiap tahunnya di seluruh dunia (Padila, 2013).

Peningkatan populasi lansia tersebut berisiko terjadinya beberapa masalah kesehatan, baik masalah fisik, mental, sosial, dan timbulnya berbagai penyakit degenerative (Wahjudi, 2009). Masalah kesehatan ini akan membebani perekonomian baik pada lansia maupun pada pemerintah. Beban ekonomi ini disebabkan penyakit tersebut banyak memerlukan dana untuk terapi dan rehabilitasinya. Sehingga, lansia dituntut memeriksa kesehatan secara rutin untuk mengetahui lebih awal penyakit yang diderita atau ancaman masalah kesehatan yang dihadapi (Kementrian Kesehatan RI, 2012).

Masalah kesehatan yang dihadapi sebagian besar lansia yaitu memiliki kesulitan pada upaya mereka untuk mengatasi proses penuaan. Proses penuaan merupakan suatu proses alami yang tidak dapat dicegah dan merupakan hal yang wajar dialami oleh orang yang diberi karunia umur panjang, dimana semua orang berharap akan menjalani hidup dengan tenang, damai, serta menikmati masa pensiun bersama anak dan cucu tercinta dengan penuh kasih sayang (Hamid, 2006). Tidak semua lansia dapat menjalani hidup dengan tenang. Proses menua tetap menimbulkan permasalahan baik secara fisik, biologis, mental maupun sosial ekonomi (Azizah, 2011). Lansia yang mempunyai masalah kesehatan akan menurunkan kualitas hidup dan disinilah pentingnya adanya Panti Werdha/ Lembaga Kesejahteraan Sosial.

Panti werdha sebagai tempat untuk pemeliharaan dan perawatan bagi lansia mempunyai peran penting untuk menyelesaikan masalah-masalah mereka (Elvinia, 2006). Pada awalnya intitusi ini dimaksudkan untuk menampung lansia yang miskin dan terlantar untuk diberikan fasilatas yang layak. Fenomena saat ini 
panti juga disini oleh orang yang berkecukupan. Hal ini disebabkan oleh faktor perubahan tipe keluarga, perubahan peran ibu dan kebutuhan sosialisasi lansia (Hamid, 2006). Akan tetapi, banyak peneliti sebelumnya mengatakan bahwa kualitas hidup lansia yang tinggal di panti lebih rendah daripada di rumah (Elvinia, 2006).

Kualitas hidup adalah persepsi individu mengenai posisi di dalam hidup dalam konteks kebudayaan dan sistem-sistem nilai, pada tempat tinggalnya dan berhubungan dengan tujuan, harapan, standar, dan konsentrasi mereka (World Health Organization, 2015). Terdapat empat domain dalam kualitas hidup adalah kesehatan fisik, kesehatan psikologi, hubungan sosial, dan aspek lingkungan (WHOQOL Group; Jackie Brown, 2004). Empat domain kualitas hidup diidentifikasi sebagai suatu perilaku, status keberadaan, kapasitas potensial, dan persepsi atau pengalaman subjektif (WHOQOL Group, 1994). Ratna (2008) juga menambahkan jika kebutuhan-kebutuhan tersebut tidak terpenuhi, akan timbul masalah-masalah dalam kehidupan lansia yang akan menurunkan kualitas hidupnya.

Saat ini, diseluruh dunia jumlah lansia diperkirakan ada 500 juta dengan usia rata-rata 60 tahun dan diperkirakan pada tahun 2025 akan mencapai 1,2 milyar. Di negara maju seperti Amerika serikat pertambahan orang lansia diperkirakan 1000 orang per hari pada tahun 1995 dan di perkirakan 50\% dari penduduk berusia diatas 50 tahun (Padila, 2013).

Menurut WHO (2010), di kawasan Asia Tenggara 8\% populasi adalah lansia atau sekitar 140 juta jiwa. Pada tahun 2050 diperkirakan usia harapan hidup di sebagian besar Asia Tenggara akan menjadi >75 tahun. Pada tahun 2009 penduduk lansia di Indonesia berjumlah 20.547.541 jiwa. Di perkirakan jumlah penduduk lansia di Indonesia pada tahun 2020 akan mencapai 28,8 juta jiwa atau sekitar 11\% dari total penduduk Indonesia (Depkes RI, 2013). Hasil sensus penduduk 2010 menunjukkan bahwa Indonesia termasuk lima besar negara dengan jumlah penduduk lansia terbanyak di dunia yakni mencapai 18,1 juta jiwa atau 9,6\% dari jumlah penduduk (Badan Pusat Statistik, 2013). 
Berdasarkan data dari Dinas Kesehatan Provinsi Kepulauan Riau tahun 2013, jumlah lansia yang di bina sebesar 59.142 jiwa atau 94\% dari seluruh populasi lansia yang jumlahnya mencapai 62.862 jiwa. Sedangkan data dari Dinas Kesehatan Kota Tanjungpinang tahun 2013, jumlah lansia yang dibina sebesar 41.473 jiwa atau $89 \%$ dari seluruh populasi lansia yang jumlahnya mencapai 46.167 jiwa. Lansia-lansia tersebar di komunitas dan di Lembaga Kesejahteraan Lansia di Tanjungpinang.

Hasil studi pendahuluan pada tanggal 28 April 2016, lembaga kesejahteraan lansia di Tanjungpinang ada 3 yaitu lembaga kesejahteraan bahagia Kawal yang jumlah lansianya 40 lansia, lembaga kesejahteraan Embung Fatimah dengan jumlah lansia 7 lansia dan lembaga kesejahteraan Anugerah dengan jumlah lansia 27 lansia. Dari tiga lembaga kesejahteraan lansia Anugerah di Tanjungpinang belum mengaktifkan senam lansia dalam pelayanan.

Berdasarkan hasil penelitian yang dilakukan oleh (Rahayu, 2008) didapatkan ada hubungan senam lansia terhadap kualitas hidup. Hal ini sesuai dengan penelitian yang dilakukan oleh Acree dan Longfors (2006) yaitu melakukan pengukuran kualitas hidup dengan pada kelompok lansia yang melakukan aktivitas tinggi dan kelompok lansia yang melakukan aktivitas rendah. Hasilnya kelompok lansia yang melakukan aktivitas tinggi memiliki skor kualitas hidup lebih tinggi dibandingkan dengan kelompok lansia yang melakukan aktivitas rendah. Hal ini dapat disimpulkan bahwa terjadi peningkatan jumlah aktivitas pada lansia dapat meningkatkan kualitas hidup lansia seperti senam lansia.

\section{BAHAN DAN METODE}

Lokasi Penelitian ini adalah Lembaga Kesejahteraan Lansia Anugerah Tanjungpinang-Kepulauan Riau. Metode penelitian ini menggunakan desain quasi experiment, rancangan pre and post-test without control group. Populasi seluruh lansia di Lembaga kesejahteraan lansia Anugerah sebanyak 27 lansia. Untuk 
mengantisipasi loss of sample ditambahkan $10 \%$ dari $2 \&$ lansia sehingga jumlah sampel dalam penelitian ini berjumlah 10 lansia.

Teknik sampling dengan simple random sampling. Lansia yang memenuhi kriteria inklusi yaitu responden berumur 55 tahun, tidak memiliki penyakit penyerta (stroke, reumatoid), konigtif yang baik (MMSE $<23$ ) dan kriteria eksklusi adalah lansia yaang mengalami masalah kesehatan mobilitas fisik, kognitf dan mental, lansia yang tidak tinggal di lembaga kesejahteraan lansia. Ada dua analisa data yang digunakan di penelitian ini yaitu univariat adalah distribusi frekuensi dan persentase dari setiap variabel yaitu umur lansia, jenis kelamin. Analisis data bivariat menggunakan Uji Independent $t$-test .

\section{HASIL DAN BAHASAN}

Hasil penelitian, terdapat data kategorik dan data numerik. Data kategorik adalah pengaplikasian berupa data, tulisan, kategori. Disajikan dalam bentuk jumlah atau frekuensi dan persentase (\%).

Tabel 1

\section{Karakteristik berdasarkan jenis kelamin dan umur}

\begin{tabular}{lll}
\hline Variabel & n & \% \\
\hline Jenis Kelamin : & & \\
-Laki-laki & 5 & 50 \\
-Perempuan & 5 & 50 \\
\hline Umur : & & \\
- Usia pertengahan (45-59) & 4 & 40 \\
- Lanjut usia (60-74) & 4 & 40 \\
- Lanjut usia tua (75-90) & 2 & 20 \\
\hline & Mean: 65.5 & SD: 5.67 \\
\hline Pendidikan & & \\
- SD & 7 & 70 \\
- SMP & 3 & 30 \\
\hline Pekerjaan & & \\
- Tidak bekerja & 9 & 90 \\
- Bekerja & 1 & 10 \\
Status Pernikahan & & \\
- Belum menikah & 6 & 60 \\
- Menikah & 4 & 40 \\
\hline
\end{tabular}


Tabel 1 menunjukkan bahwa dari 10 lansia dengan tinggal di Lembaga kesejahteraan lansia anugerah, lebih dari sebagian 5 orang $(50 \%)$ berjenis kelamin perempuan, sementara lebih dari sebagian juga 4 orang (40\%) berada kategori usia pertengahan dengan tingkat pendidikan SD sebanyak 7 orang (70\%). Mayoritas lansia yang berada di lembaga kesejahteraan tidak bekerja 9 orang $(90 \%)$ serta sebagian lansia belum menikah 6 orang $(60 \%)$.

Tabel 2

Distribusi kualitas hidup lansia sebelum dan sesudah perlakuan pada lansia di Lembaga Kesejahteran Lansia Anugerah Tahun 2016

\begin{tabular}{lcc}
\hline No & $\begin{array}{c}\text { Kualitas hidup } \\
\text { (Sebelum) }\end{array}$ & $\begin{array}{c}\text { Kualitas hidup } \\
\text { (Sesudah) }\end{array}$ \\
\hline 1 & Baik & Sangat baik \\
\hline 2 & Kurang Baik & Baik \\
\hline 3 & Baik & Baik \\
\hline 4 & Kurang Baik & Sangat baik \\
\hline 5 & Kurang Baik & Baik \\
\hline 6 & Baik & Sangat baik \\
\hline 7 & Baik & Sangat baik \\
\hline 9 & Kurang Baik & Baik \\
\hline 10 & Baik & Sangat baik \\
\hline
\end{tabular}

Tabel 2 menunjukkan hasil kualitas hidup lansia di lembaga kesejahteraan lansia Anugerah sebelum di lakukan intervensi senam lansia adalah kurang baik $5(50 \%)$. Setelah dilakukan intervensi senam sebagian dari lansia kualitas hidupnya adalah sangat baik $5(55.6 \%)$

Analisis bivariat dalam penelitian ini menggunakan uji independent sample t-test. Berdasarkan perhitungan dengan program perangkat lunak komputer, diperoleh hasil analisa bivariat sebagai berikut: 
Tabel 3

Analisis kualitas hidup lansia sebelum dan sesudah perlakuan di lembaga kesejahteraan sosial lansia Anugerah Tanjungpinang

\begin{tabular}{cccccc}
\hline Variabel & Mean & SD & Min & Max & Value \\
\hline Kualitas hidup sebelum & 31.11 & 4.076 & 22 & 31 & \\
\hline $\begin{array}{c}\text { Kualitas hidup } \\
\text { sesudah }\end{array}$ & 36.11 & 4.410 & 35 & 43 & 0,014 \\
\hline
\end{tabular}

Berdasarkan tabel 3 di atas, hasil analisis tersebut menunjukkan bahwa terjadi penurunan nilai rata-rata kualitas hidup di Lembaga kesejahteraan lansia Anugerah sebelum perlakuan (pre-test) 31,11 dan setelah perlakuan (post-test) adalah 36,11 . Terlihat perbedaan nilai kualitas hidup antara responden sebelum dan sesudah dengan uji statistik $p$ value sebesar 0,014 sehingga dapat disimpulkan bahwa ada perbedaan yang signifikan terhadap kualitas hidup responden sebelum dan setelah perlakuan. Hal ini berarti bahwa senam lansia pada lansia dapat meningkatkan kualitas hidup lansia di lembaga kesejahteraan lansia anugerah.

Hasil penelitian didapatkan bahwa sebagian lansia berjenis kelamin perempuan, hal ini sejalan dengan Badan Pusat Statistik Kepri (BPS) (2014) didapatkan jumlah lansia yang berjenis kelamin perempuan lebih banyak dari lakilaki yaitu sebanyak 657 per 1000 pernduduk. Jenis kelamin menemukan adanya perbedaan antara kualitas hidup antara laki-laki dan perempuan, dimana kualitas hidup laki-laki cenderung lebih baik daripada kualitas hidup perempuan. Sementara lebih dari sebagian juga berada kategori usia pertengahan. Usia pertengahan merupakan usia yang mulai mengalami masa produktif dan mengalami penurunan baik masalah fisik, dan psikologi (Samlee, 2015). Menurut Depkes (2013) lansia merupakan seseorang yang memasuki usia 60 tahun. Usia adalah salah satu faktor yang mempengaruhi kualitas hidup. Majoritas tingkat pendidikan Sekolah Dasar (SD), hal ini sejalan dengan data BPN (2014) dimana mayoritas penduduk di Tanjungpinang berpendidikan SD. Pendidikan adalah kualitas hidup akan meningkat seiring dengan lebih tingginya tingkat pendidikan yang didapatkan oleh individu. 
Mayoritas lansia yang berada di Panti Werdha (lembaga Kesejahteraan) tidak bekerja, data yang didapat dari lembaga kesejaheraan anugerah dimana lansia yang tinggal disini merupaka lansia yang terlantar dan lansia yang dibawa oleh Dinas Sosial Tanjugpinang. Pekerjaan mengatakan perbedaan kualitas hidup antara penduduk yang berstatus sebagai pelajar, penduduk yang bekerja, penduduk yang tidak bekerja (atau sedang mencari pekerjaan), dan penduduk yang tidak mampu bekerja (atau memiliki disablitas tertentu). Hasil penelitian juga menemukan lansia yang belum menikah. Status pernikahan mengatakan bahwa terdapat perbedaan kualitas hidup antara individu yang tidak menikah, individu bercerai ataupun janda, dan individu yang menikah atau kohabitasi. Penghasilan menemukan adanya pengaruh dari faktor demografi berupa penghasilan dengan kualitas hidup yang dihayati secara subjektif. Hubungan dengan orang lain menemukan adanya pengaruh dari faktor demografi berupa faktor jaringan sosial dengan kualitas hidup yang dihayati secara subjektif.

Hasil penelitian ini didapatkan bahwa ada perbedaan yang signifikan terhadap kualitas hidup responden sebelum dan setelah dilakukan senam lansia. Kualitas hidup diartikan Sebagai persepsi individu mengenai keberfungsian mereka di dalam bidang kehidupan (Nofitri, 2009). Ada empat aspek dari kualitas hidup yaitu fisik, psikologik, sosial dan lingkungan. Lingkungan tempat lansia tinggal secara langsung dapat mempengaruhi kualitas hidup. Lembaga kesejahteran lansia merupakan salah satu tempat menampung atau merawat lansia. Lembaga kesejahteran lansia adalah salah satu bentuk pemerintah kepada masyarakat yang telah berusia lanjut. Dibanyak negara memasukkan lansia di lembaga kesejahteran lansia merupakan suatu gaya hidup, namun kita sebagai orang timur yang adat dan kebudayaannya masih kental, memelihara, menjaga dan merawat orang tua adalah suatu kewajiban. Perawatan lansia di lembaga kesejahteraan dapat ditingkatkan dengan melakukan berbagai aktivitas untuk mengisi waktu luangnya.

Aktivitas yang dapat dilakukan secara rutin di lembaga kesejahteraan yaitu senam. Senam merupakan olahraga ringan dan mudah dilakukan, tidak memberatkan yang diterapkan pada lansia (Poweel, 2015). Aktifitas olahraga ini 
akan membantu tubuh agar tetap bugar dan tetap segar karena melatih tulang tetap kuat, mendorong jantung bekerja optimal dan membantu menghilangkan radikal bebas yang berkeliaran didalam tubuh. Hasil penelitian yang dilakukan oleh (Rahayu, 2008) didapatkan ada hubungan senam lansia terhadap kualitas hidup. Hal ini sesuai dengan penelitian yang dilakukan oleh Acree dan Longfors (2006) yaitu melakukan pengukuran kualitas hidup dengan pada kelompok lansia yang melakukan aktivitas tinggi dan kelompok lansia yang melakukan aktivitas rendah. Hasilnya kelompok lansia yang melakukan aktivitas tinggi memiliki skor kualitas hidup lebih tinggi dibandingkan dengan kelompok lansia yang melakukan aktivitas rendah. Hal ini dapat disimpulkan bahwa terjadi peningkatan jumlah aktivitas pada lansia dapat meningkatkan kualitas hidup lansia yaitu senam lansia.

\section{SIMPULAN DAN SARAN}

Hasil penelitian ini menunjukkan bahwa lansia di Lembaga Kesejahteraan Lansia Anugerah sebagian berjenis kelamin perempuan, sementara lebih dari sebagian berada kategori usia pertengahan dengan tingkat pendidikan Sekolah Dasar. Mayoritas lansia yang berada di panti werdha tidak bekerja serta sebagian lansia belum menikah. Ada perbedaan yang signifikan terhadap kualitas hidup responden sebelum dan setelah dilakukan senam lansia. Hasil penelitian ini diharapkan dapat meningkatkan kualitas hidup lansia di Lembaga Ksejahteraan Sosial Anugerah. Kualitas hidup lansia dapat meningkat dengan cara melaksanakan senam lansia secara teratur dan berkesimbungan.

\section{RUJUKAN}

Acree dan Longfros (2006). Domain of Quality of life. Journal health reseach: 5(8), 251-359.

Arikunto, S (2013). Prosedur penelitian: Suatu pendekatan Praktik. Jakarta: Rineka Cipta.

Azizah, L.M (2011). Keperawatan lanjut usia. Yogjakarta: Pustaka Pelajar.

Bangun, W (2008). Intisari manajamen. Bandung: PT. Refika Aditama. 
BPS (2013). Data penduduk 2013. Didapat dari www.BPS.go.id.

Depkes RI (2013). Masalah kesehatan pada lansia. Didapat dari www.depkesri.go.id

Elviana (2006). Senam pada lansia. Jakarta : EGC.

Famitah (2010). Merawat Manusia Lanjut Usia. Jakarta: Cv Trans Info Media.

Ginting (2011). Kualitas hidup masyarasat Indonesia dalam pendekatan psikologi. Journal ners.

Hamid .(2006). Psikologi pada lansia. Jakarta: Rineka cipta.

Jackie, brown (2006). Quality of Life for Geriatric. Journal health reseach: 5(8), 345-352.

Kementrian kesehatan RI (2012). Data kesehatan Indonesia, didapat dari www.riskesdas.go.id

Mubarak, et al. (2011). Ilmu keperawatan komunitas konsep dan aplikasi. Yogjakarta: Graha ilmu.

Nofitri, Alimul H. (2009). Kualitas hidup penduduk dewasa di jakarta.didapat dari www.repository.usu.ac.id.

Notoatmojo, S. (2007). Metodologi penelitian kesehatan. Jakarta: Pt. Rineka Cipta.

Padila (2013). Buku Ajar Keperawatan gerontik. Yogjakarta: Nusa Medika.

Poweel, J.E.(2015).Senam. Jakarta: Gramedia Pustaka

Rahayu (2008). Kualitas hidup lansia di posbindu lansia pergeri. Didapat di www.eprintums.ac.id

Ratna (2008). Mengenal lansia dan perawatanya. Jakarta: Selemba medika 
Suroto (2007). Buku penganan kuliah: pengertian senam, manfaat senam dan urutan. Jakarta: KOMNAS LANSIA

Wahyudi, Nugoroho (2009). Gangguan tidur pada lansia: diagnosis dan perawatan.jakarta: EGC 